Article

\title{
Polyphenolic Profile and Antioxidant Capacity of Extracts from Gordonia axillaris Fruits
}

\author{
Ya Li ${ }^{1,+}+$, Shi-Yu Cao ${ }^{1,+}$, Sheng-Jun Lin ${ }^{2}$, Jia-Rong Zhang ${ }^{3}$, Ren-You Gan ${ }^{3, *}$ and \\ Hua-Bin $\mathrm{Li}^{1}$ * \\ 1 Guangdong Provincial Key Laboratory of Food, Nutrition and Health, Department of Nutrition, School of \\ Public Health, Sun Yat-Sen University, Guangzhou 510080, China; liya28@mail3.sysu.edu.cn (Y.L.); \\ caoshy3@mail2.sysu.edu.cn (S.-Y.C.) \\ 2 Zhongshan Center for Disease Control and Prevention, Zhongshan 528403, China; zscdclsj@163.com \\ 3 Department of Food Science \& Technology, School of Agriculture and Biology, Shanghai Jiao Tong University, \\ Shanghai 200240, China; zhangjiarong@sjtu.edu.cn \\ * Correspondence: renyougan@sjtu.edu.cn (R.-Y.G.); lihuabin@mail.sysu.edu.cn (H.-B.L.); \\ Tel.: +86-21-3420-8517 (R.-Y.G.); +86-20-873-323-91 (H.-B.L.) \\ + The authors contributed equally to this work.
}

Received: 15 April 2019; Accepted: 26 May 2019; Published: 29 May 2019

check for updates

\begin{abstract}
An ultrasonic-assisted extraction (UAE) method was adopted to extract natural antioxidants from edible Gordonia axillaris fruit. Single-factor experiments and response surface methodology were conducted to investigate the influences of five different parameters on antioxidant capacity. The optimal conditions of the UAE were $39.78 \%$ ethanol, $30.94 \mathrm{~mL} / \mathrm{g}$ solvent/material ratio, $59.47 \mathrm{~min}$ extraction time, $40{ }^{\circ} \mathrm{C}$ temperature, and $400 \mathrm{~W}$ ultrasonication power. The antioxidant capacity was $525.05 \pm 14.34 \mu \mathrm{mol}$ Trolox/g DW under the optimal conditions, which was in agreement with the predicted one $(531.71 \mu \mathrm{mol}$ Trolox/g DW). Additionally, in comparison with two traditional methods (maceration and Soxhlet extraction), the established UAE method greatly improved the yield of antioxidants and significantly reduced the extraction time. Besides, nine phenolic compounds were identified and quantified in the extract of Gordonia axillaris fruits by ultra-performance liquid chromatography-tandem mass spectrometry (UPLC-MS/MS), including rutin, gallic acid, protocatechuic acid, epicatechin, 2-hydrocinnamic acid, $p$-coumaric acid, quercetin, epicatechin gallate, and ferulic acid. The richness of phenolic compounds in the Gordonia axillaris fruits indicated its potential health benefits, and its extract rich in antioxidants could be developed into functional food or nutraceuticals with the potential to prevent certain diseases induced by oxidative stress, such as cardiovascular diseases and cancers. This study also provided a way to enhance the economic values of Gordonia axillaris fruits compared to raw fruits.
\end{abstract}

Keywords: Gordonia axillaris; ultrasonic-assisted extraction; antioxidant; phenolic compound; response surface methodology

\section{Introduction}

Many fruits have been found rich in phenolic compounds, which have been reported to possess antioxidant, antimicrobial, and anti-inflammatory activities [1,2]. Gordonia axillaris is widely distributed in southern America and China, such as Hong Kong, Sichuan, Yunnan, Hainan, and Guangxi provinces [3]. The trees of Gordonia axillaris are evergreen shrubs or small tree plants which can grow up to eight meters (Figure 1a), and are often planted as garden tree due to their attractive appearance. The different parts of Gordonia axillaris, including fruit, leaf, and stem bark, have been used in the traditional folk medicine for the treatment of certain ailments, such as stomachaches and diarrhea $[4,5]$. 
In addition, their anticancer and hepatoprotective activities have also been reported [3,6]. The fruit of Gordonia axillaris is an edible wild fruit, mainly used in herbal medicine. The fruit appears as a rough oval with a length about $2 \mathrm{~cm}$ and a width about $1 \mathrm{~cm}$ (Figure 1b). In our previous study, the fruits of Gordonia axillaris were found to possess strong antioxidant capacity with TEAC value $344 \pm 12.1 \mu \mathrm{mol}$ Trolox/g, TPC value $24.6 \pm 1.08 \mathrm{mg}$ GAE/g, FRAP value $180 \pm 11.2 \mu \mathrm{mol} \mathrm{Fe}(\mathrm{II}) / \mathrm{g}$ based on tetrahydrofuran and methanol-acetate acid-water (50:3.7:46.3, v/v/v) extraction [7], suggesting that the Gordonia axillaris fruits can be a potential rich source of natural antioxidants. Furthermore, cultivation of this tree has increased in recent years due to the increasing economic and health potentials of the tree and its fruit. Since the extraction efficiency is the guarantee to recover bioactive components from the fruits, developing an efficient method to extract antioxidants, especially the phenolic compounds, from Gordonia axillaris fruit is critical for its value-added utilization.

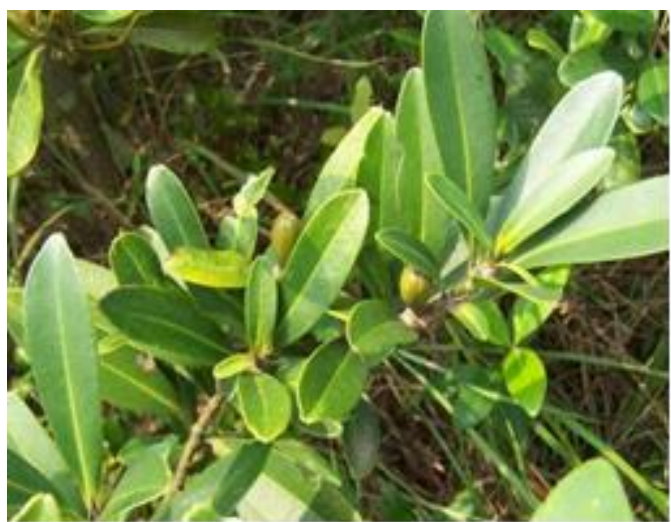

(a)

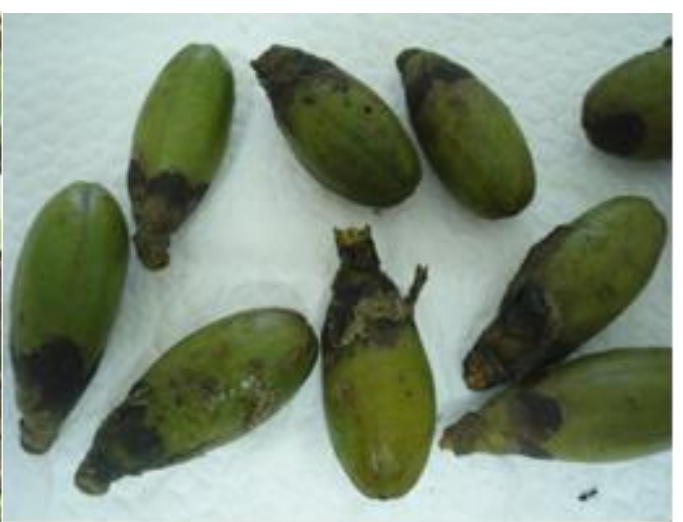

(b)

Figure 1. (a) The trees of Gordonia axillaris; (b) The fruits of Gordonia axillaris.

A microwave-assisted extraction method was developed to extract antioxidants from this fruit previously [8]. Ultrasonic-assisted extraction (UAE) is another green and efficient extraction technique [9, 10]. Thus, it is necessary to develop an alternative extraction method using UAE to extract antioxidants from this fruit, and to compare its extraction efficiency with conventional methods. Generally, the mechanisms of UAE have been mainly considered as a result of cavitation phenomena occurring during ultrasonic irradiation [11,12]. Recently, it has been pointed out that UAE works through various independent or combined mechanisms between fragmentation, capillarity, erosion, sonoporation, and detexturation [13]. In comparison with some conventional extraction methods such as maceration and hot reflux extraction, UAE has several advantages such as shorter extraction time, reduced organic solvent consumption, and less energy costs [14,15]. Therefore, UAE has been utilized to extract many bioactive components from natural products such as fruits [16,17].

During the UAE procedure, the extraction efficacy would be influenced by several parameters, such as the solvent, extracting time, and temperature [13]. These parameters could also interact with each other, affecting the extraction efficacy in a more complex way. Therefore, it is important to evaluate the interactions among these parameters, and response surface methodology (RSM) could be adopted to optimize the parameters and obtain the maximum yields of target compounds [18-20].

Compared to the raw fruit, the content of bioactive components in the extract could be increased obviously, and the volume and weight of the extract could be decreased markedly. Therefore, the effective concentration of bioactive compounds could be reached more easily by intake of the extract than consumption of the raw fruit. The present study is aimed at establishing an efficient UAE method to extract natural antioxidants from the Gordonia axillaris fruits. Moreover, ultra-high-performance liquid chromatography coupled with tandem mass spectrometry (UPLC-MS/MS) was adopted to identify and quantify main phenolic compounds in the extract. Compared to the raw fruits, Gordonia axillaris fruit extracts can be concentrated in natural antioxidants, which can be used as high-value 
functional ingredients or additives to formulate different functional foods or nutraceuticals with the potential to prevent certain diseases related to oxidative stress.

\section{Materials and Methods}

\subsection{Chemicals and Reagents}

The Folin-Ciocalteu's phenol reagent, standard phenolic compounds (2-hydrocinnamic acid, rutin, daidzein, equol, coffeic acid, $p$-coumaric acid, epigallocatechin, quercetin, ferulic acid, epicatechin, glycitein, resveratrol, chlorogenic acid, gallic acid, epicatechin gallate, genistein, and protocatechuic acid), ABTS (2,2'-azinobis(3-ethyl-benothiazoline-6-sulphonic acid) diammonium salt), and Trolox (6-hydroxy-2,5,7,8-tetramethylchromane-2-carboxylic acid) were purchased from Sigma-Aldrich (St. Louis, MO, USA). Potassium acetate, potassium persulphate, aluminum chloride hexahydrate, and sodium carbonate were purchased from Tianjin Chemical Factory (Tianjin, China). The formic acid and methanol of HPLC grade were used for the UPLC-MS/MS analysis. Besides, all other chemicals and reagents used in this work were of analytical grade, and deionized water was used in all the experiments.

\subsection{Sample Preparation}

The ripe Gordonia axillaris fruits with overall the same maturity stage were manually collected from different Gordonia axillaris trees at the Lung Fu Mountain, Sai Wan, Hong Kong Island, Hong Kong, in August 2017. The fruit was ground into fine particles by a pulverizer (model XT-A400, Hongtaiyang Co., Ltd., Yongkang, China), freeze-dried, sieved ( $0.300 \mathrm{~mm}$ particle size), and then stored at $4{ }^{\circ} \mathrm{C}$ in a refrigerator.

\subsection{Instruments}

The extraction of antioxidants from Gordonia axillaris fruit was carried out in an ultrasonic bath device (Kj1012B, Guangzhou Kejin Ultrasonic Instrument Factory, Guangzhou, China). The device was equipped with a digital control system for working time, temperature, and irradiation power, with an ultrasonic frequency of $28 \mathrm{kHz}$, and the temperature is controlled using a water bath with a thermocouple in this device.

\subsection{Extraction of Antioxidants}

\subsubsection{Ultrasonic-Assisted Extraction}

The powder of Gordonia axillaris fruits $(0.500 \mathrm{~g})$ was accurately weighed and mixed with a certain volume of ethanol-water solution in a tube, with the concentration based on the experimental design. Then, the tubes were immersed into a sonication water bath, and irradiated under different temperatures $\left({ }^{\circ} \mathrm{C}\right)$, ultrasonication powers $(\mathrm{W})$, and extraction time $(\mathrm{min})$, as defined by the experimental design. After the extraction, the mixture was centrifuged $\left(4200 \times g, 15 \mathrm{~min}\right.$, and $\left.4{ }^{\circ} \mathrm{C}\right)$, and the supernatant was collected and stored at $4{ }^{\circ} \mathrm{C}$ for further use. Additionally, the supernatant was filtered $(0.45 \mu \mathrm{m}$ membrane) prior to UPLC-MS/MS analysis.

\subsubsection{Maceration Extraction}

The powder of Gordonia axillaris fruits $(0.500 \mathrm{~g})$ was extracted with $15.47 \mathrm{~mL}$ of $39.78 \%$ ethanol for $24 \mathrm{~h}$ at room temperature $\left(25^{\circ} \mathrm{C}\right)$ in a shaking water bath. After the extraction, the mixture was centrifuged $\left(4200 \times g, 15 \mathrm{~min}\right.$, and $\left.4{ }^{\circ} \mathrm{C}\right)$, and the supernatant was collected for further analysis.

\subsubsection{Soxhlet Extraction}

The Soxhlet extraction was conducted according to the method reported previously [15]. The powder of Gordonia axillaris fruits $(0.500 \mathrm{~g})$ was wrapped with Whatman filter paper and extracted 
with $400 \mathrm{~mL}$ of ethanol aqueous solution (39.78\%) in a Soxhlet apparatus. After $4 \mathrm{~h}$ of extraction under $85^{\circ} \mathrm{C}$ (maintained by a water bath), the obtained solution was collected for the subsequent analysis.

\subsection{Determination of Antioxidant Capacity}

Trolox equivalent antioxidant capacity (TEAC) assay was used to evaluate the antioxidant capacity of the extracts from the Gordonia axillaris fruits, and the procedure was carried out according to the literature [21]. In short, the ABTS stock solution was prepared by mixing $2.45 \mathrm{mmol} / \mathrm{L}$ potassium persulfate solution and $7 \mathrm{mmol} / \mathrm{L} \mathrm{ABTS}^{\bullet+}$ solution $(1: 1, \mathrm{v} / \mathrm{v})$, and placed in the dark for $16 \mathrm{~h}$ before use. To test the sample, the ABTS working solution was prepared by diluting the ABTS stock solution with deionized water to make the absorbance at $0.70 \pm 0.05$ at $734 \mathrm{~nm}$. Subsequently, a $0.1 \mathrm{~mL}$ sample was mixed with $3.8 \mathrm{~mL}$ diluted ABTS working solution for $6 \mathrm{~min}$, and then the absorbance of the mixture was tested using a spectrophotometer (Model 722, Shanghai precision instrument Co., Ltd., Shanghai, China). Trolox was used as the reference compound, and the TEAC results were expressed as $\mu \mathrm{mol}$ Trolox/g dry weight (DW) of Gordonia axillaris fruits.

\subsection{Determination of the Yield of Phenolic Compounds}

In this study, the yield of phenolic compounds was determined by evaluating the total phenolic contents (TPC) in extracts. The TPC was determined based on the method reported in the previous literature [22]. Briefly, a $0.5 \mathrm{~mL}$ diluted sample was mixed with $2.5 \mathrm{~mL} 0.2 \mathrm{~mol} / \mathrm{L}$ Folin-Ciocalteu reagent for $4 \mathrm{~min}$, and then $2 \mathrm{~mL}$ saturated sodium carbonate solution $(75 \mathrm{~g} / \mathrm{L})$ was added into the solution. After $2 \mathrm{~h}$ of incubation at room temperature, the absorbance of the solution was measured at $760 \mathrm{~nm}$. Gallic acid was used as the reference compound, and the results of TPC were displayed as mg gallic acid equivalent (GAE)/g DW of Gordonia axillaris fruits.

\subsection{Determination of the Yield of Flavonoid Compounds}

The total flavonoid content (TFC) in the extract was evaluated according to the method reported in the previous literature [23]. In brief, a $0.5 \mathrm{~mL}$ sample was added to the solution containing $1.5 \mathrm{~mL}$ ethanol $(95 \%, \mathrm{v} / \mathrm{v}), 0.1 \mathrm{~mL} \mathrm{AlCl} 3$ solution $(10 \%, \mathrm{w} / \mathrm{v}), 0.1 \mathrm{~mL}$ potassium acetate solution $(1 \mathrm{~mol} / \mathrm{L})$, and $2.8 \mathrm{~mL}$ deionized water. The solution was incubated for $30 \mathrm{~min}$ before testing the absorbance at $415 \mathrm{~nm}$. Quercetin was used as the reference compound, and the results of TFC were expressed as mg quercetin equivalent (mg QE)/g DW of Gordonia axillaris fruits.

\subsection{Analysis of Phenolic Compounds by UPLC-MS/MS}

The phenolic compounds in the extracts obtained under the optimal condition of UAE were analyzed based on the method described in the previous literature with minor modifications [17]. An AB SCIEX 4000 QTRAP LC-MS/MS system (SCIEX, Framingham, MA, USA) was employed, equipped with an Acquity UPLC ${ }^{\circledR}$ HSS T3 column $(3.0 \times 150 \mathrm{~mm}, 1.8 \mu \mathrm{m})$ (Waters, Milford, MA, USA) for the separation of phenolic compounds at $40{ }^{\circ} \mathrm{C}$, and the injection volume was $2 \mu \mathrm{L}$. The mobile phase consisted of solution A ( $0.2 \%$ formic acid aqueous solution) and solution B (methanol), and the flow rate was $0.3 \mathrm{~mL} / \mathrm{min}$. The gradient elution was performed as follows: $0-2 \mathrm{~min}, 15 \%$ (B); 2-8 min, 15-30\% (B); 8-15 min, 30-80\% (B); 15-17.5 min, 80\% (B); 17.5-19.5 min, 15\% (B). For the conditions of MS, ESI source with the negative mode was selected and ion source temperature was 550 ${ }^{\circ} \mathrm{C}$. The capillary voltage was $-4,500 \mathrm{~V}$ and multiple reaction monitoring (MRM) mode was selected. The curtain gas, nebulizer gas, and auxiliary gas was 12, 20, and 20 psig, respectively. The phenolic compounds were tentatively identified by MS/MS, and further verified and quantified by comparing the retention time and peak area with those of the standards. The contents of phenolic compounds were expressed as $\mu \mathrm{g} / \mathrm{g} \mathrm{DW}$. 


\subsection{Experimental Design}

\subsubsection{Single-Factor Experiments}

Single-factor experiments were carried out to evaluate the effects of five experimental parameters on the extraction efficacy, including ethanol concentration (20-80\%), solvent/material ratio (S/M ratio, $10-60 \mathrm{~mL} / \mathrm{g})$, extraction time $(0-90 \mathrm{~min})$, extraction temperature $\left(30-70{ }^{\circ} \mathrm{C}\right)$, and ultrasonication power $(300-800 \mathrm{~W})$. Based on the results from single-factor experiments, three factors showing major influences on the extraction efficacy would be selected in the subsequent response surface method design.

\subsubsection{Response Surface Methodology (RSM)}

The RSM was conducted through a central composite rotatable design (CCRD) to optimize the yield of antioxidants from the Gordonia axillaris fruits. Based on the results of single-factor experiments, three independent variables, including ethanol concentration $(X 1, \%), S / M$ ratio $(X 2, \mathrm{~mL} / \mathrm{g})$, and extraction time (X3, min), were selected for the RSM design. Three independent variables and their related codes and levels are displayed in Table 1. A three-factor, five-level CCRD with 20 experimental runs were carried out, including six replicates in the central point (Table 2). The response values of the 20 different runs were fitted to the following second-order polynomial equation:

$$
Y=\beta_{0}+\sum \beta_{\mathrm{i}} X_{\mathrm{i}}+\sum \beta_{\mathrm{ii}} X_{\mathrm{i}}^{2}+\sum \beta_{\mathrm{ij}} X_{\mathrm{i}} X_{\mathrm{j}}
$$

Table 1. Five levels of the three variables of the extraction process.

\begin{tabular}{lccccccc}
\hline \multirow{2}{*}{ Variable } & \multirow{2}{*}{ Units } & \multirow{2}{*}{ Symbol } & \multicolumn{5}{c}{ Coded Levels } \\
\cline { 3 - 7 } & & & $\mathbf{- 1 . 6 8}$ & $\mathbf{- 1}$ & $\mathbf{0}$ & $\mathbf{1}$ & $\mathbf{1 . 6 8}$ \\
\hline Ethanol concentration & $\%(v / v)$ & $\mathrm{X}_{1}$ & 23.18 & 30 & 40 & 50 & 56.82 \\
Solvent/material ratio & $\mathrm{mL} / \mathrm{g}$ & $\mathrm{X}_{2}$ & 13.18 & 20 & 30 & 40 & 46.82 \\
Extraction time & $\mathrm{min}$ & $\mathrm{X}_{3}$ & 34.77 & 45 & 60 & 75 & 85.23 \\
\hline
\end{tabular}

Table 2. The experimental design, experimental value, and predicted value of RSM.

\begin{tabular}{|c|c|c|c|c|c|}
\hline \multirow{2}{*}{ Run } & \multirow{2}{*}{$\begin{array}{c}\mathrm{X}_{1}(\text { Ethanol } \\
\text { Concentration, \%) }\end{array}$} & \multirow{2}{*}{$\begin{array}{c}X_{2} \text { (Solvent/Material } \\
\text { Ratio, mL/g) }\end{array}$} & \multirow{2}{*}{$\begin{array}{c}X_{3} \text { (Extraction } \\
\text { Time, min) }\end{array}$} & \multicolumn{2}{|c|}{ Y (TEAC, $\mu$ mol Trolox/g DW) } \\
\hline & & & & Actual Value & Predicted Value \\
\hline $1 *$ & 40.00 & 30.00 & 60.00 & 511.85 & 531.11 \\
\hline 2 & 40.00 & 46.82 & 60.00 & 325.69 & 347.03 \\
\hline 3 & 56.82 & 30.00 & 60.00 & 243.01 & 256.81 \\
\hline 4 & 40.00 & 30.00 & 85.23 & 317.37 & 323.43 \\
\hline 5 & 30.00 & 40.00 & 45.00 & 423.16 & 393.22 \\
\hline 6 & 50.00 & 20.00 & 75.00 & 376.83 & 364.21 \\
\hline 7 & 30.00 & 40.00 & 75.00 & 278.25 & 259.29 \\
\hline 8 & 50.00 & 40.00 & 45.00 & 293.50 & 268.04 \\
\hline 9 & 40.00 & 30.00 & 34.77 & 275.42 & 329.54 \\
\hline 10 & 50.00 & 20.00 & 45.00 & 261.15 & 237.55 \\
\hline $11 *$ & 40.00 & 30.00 & 60.00 & 523.29 & 531.11 \\
\hline $12 *$ & 40.00 & 30.00 & 60.00 & 508.04 & 531.11 \\
\hline 13 & 40.00 & 13.18 & 60.00 & 267.60 & 306.44 \\
\hline 14 & 50.00 & 40.00 & 75.00 & 283.33 & 287.29 \\
\hline $15 *$ & 40.00 & 30.00 & 60.00 & 504.23 & 531.11 \\
\hline 16 & 23.18 & 30.00 & 60.00 & 212.50 & 258.88 \\
\hline 17 & 30.00 & 20.00 & 45.00 & 314.54 & 268.02 \\
\hline $18^{*}$ & 40.00 & 30.00 & 60.00 & 603.38 & 531.11 \\
\hline $19 *$ & 40.00 & 30.00 & 60.00 & 546.17 & 531.11 \\
\hline 20 & 30.00 & 20.00 & 75.00 & 258.61 & 241.51 \\
\hline
\end{tabular}

* stands for the six replicates of central point. 
In the equation, $X_{i}$, and $X_{j}$ stand for independent variables. $\beta_{0}, \beta_{i}, \beta_{i i}$, and $\beta_{i j}(i \neq j)$ stand for the regression coefficients for intercept, linear, quadratic, and interaction terms, respectively.

\subsection{Statistical Analysis}

In this study, all the experiments were performed in triplicate, and the results were expressed as mean value \pm standard deviation (SD). The statistical analysis was carried out using Excel 2016 (Microsoft, Redmond, WA, USA) and Design Expert (version 8.0.6, Stat-Ease, Minneapolis, MN, USA). Multiple comparisons were carried out by one-way analysis of variance (ANOVA) plus post hoc Tukey test. $P<0.05$ was defined as statistical significance.

\section{Results and Discussion}

\subsection{Results from Single-Factor Experiments}

Aqueous ethanol solution has been extensively used to extract natural bioactive compounds due to its low toxicity and easy accessibility $[24,25]$. In Figure $2 a$, the effects of different ethanol concentrations (20-80\%) on the extraction efficiency were studied, with other extraction parameters fixed as follows, $20 \mathrm{~mL} / \mathrm{g} \mathrm{S} / \mathrm{M}$ ratio, $30 \mathrm{~min}$ extraction time, $30{ }^{\circ} \mathrm{C}$ extraction temperature, and $400 \mathrm{~W}$ ultrasonication power. The yield of antioxidants increased following the increase of ethanol concentration from 20 to $40 \%$, reached its peak at ethanol concentration of $40 \%$, and then gradually decreased with the ethanol concentration from $40 \%$ to $80 \%$, which could be due to the polarity of the mixture solvent that did not match with the polarity of the extract. Similar results were found in the study using UAE to extract antioxidants from the Osmanthus fragrans flower [26] and lycopene from papaya processing waste [27]. Therefore, $40 \%$ ethanol concentration was selected in the following experiments.

The effects of different S/M ratio $(10-60 \mathrm{~mL} / \mathrm{g})$ on the TEAC value were investigated under the following conditions: $40 \%$ ethanol concentration, 30 min extraction time, $30{ }^{\circ} \mathrm{C}$ extraction temperature, and $400 \mathrm{~W}$ ultrasonication power. The results are presented in Figure $2 \mathrm{~b}$. The yield of antioxidants increased from $221.28 \pm 15.28$ to $419.01 \pm 6.32 \mu \mathrm{mol}$ Trolox/g DW as the S/M ratio rising from $10 \mathrm{~mL} / \mathrm{g}$ to $30 \mathrm{~mL} / \mathrm{g}$. A possible explanation is that higher $\mathrm{S} / \mathrm{M}$ ratio accelerated mass transfer and the diffusion of antioxidants into the solvent, thus increasing the yield of antioxidants [28,29]. However, a declining trend was observed when the $\mathrm{S} / \mathrm{M}$ ratio raised from $30 \mathrm{~mL} / \mathrm{g}$ to $60 \mathrm{~mL} / \mathrm{g}$, probably be due to the polarity difference between the mixture (including solvent and solute) and the substances to be extracted. Therefore, the $\mathrm{S} / \mathrm{M}$ ratio of $30 \mathrm{~mL} / \mathrm{g}$ was selected for the subsequent experiments.

The influences of different extraction time on the extraction efficacy were investigated in the range of 0-90 $\mathrm{min}$, with other parameters fixed as follows, $40 \%$ ethanol concentration, $30{ }^{\circ} \mathrm{C}$ extraction temperature, $30 \mathrm{~mL} / \mathrm{g} \mathrm{S} / \mathrm{M}$ ratio, and $400 \mathrm{~W}$ ultrasonication power. In Figure $2 \mathrm{c}$, as the extraction time increased from 0 to $60 \mathrm{~min}$, the TEAC value raised from $327.86 \pm 18.09$ to $497.88 \pm 6.01 \mu \mathrm{mol}$ Trolox/g DW. The maximum yield of antioxidants was obtained at $60 \mathrm{~min}$. When the extracting time further increased from 60 to $90 \mathrm{~min}$, the TEAC value began to decrease. The results suggested that in a certain range the increase in the ultrasonication time could accelerate to dissolve the target compounds, while prolonged ultrasonic irradiation time might induce to degrade some bioactive compounds. For instance, it was reported that after $80 \mathrm{~min}$ of UAE, the extraction yield of rutin from Artemisia selengensis Turcz decreased by about 13\% compared with $50 \mathrm{~min}$ of UAE [30]. Similar results were also found in the study of extracting oleanolic acid and ursolic acid from Ligustrum lucidum Ait using UAE [31]. Therefore, the extracting time of $60 \mathrm{~min}$ was chosen for the following experiments. 


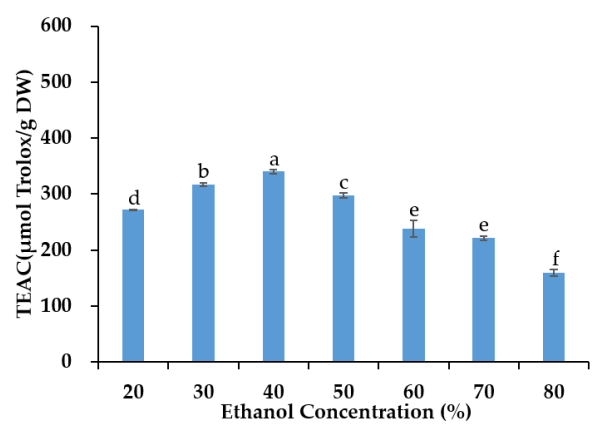

(a)

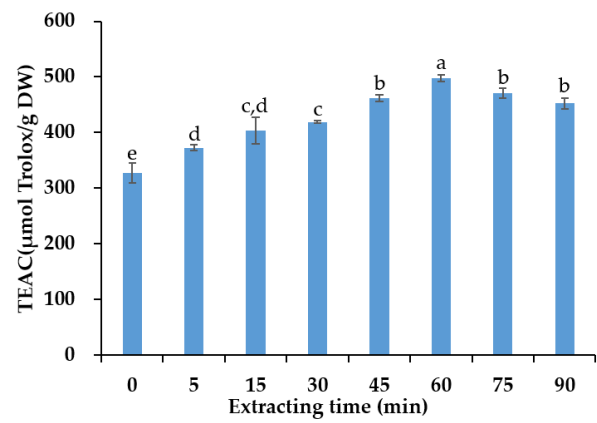

(c)

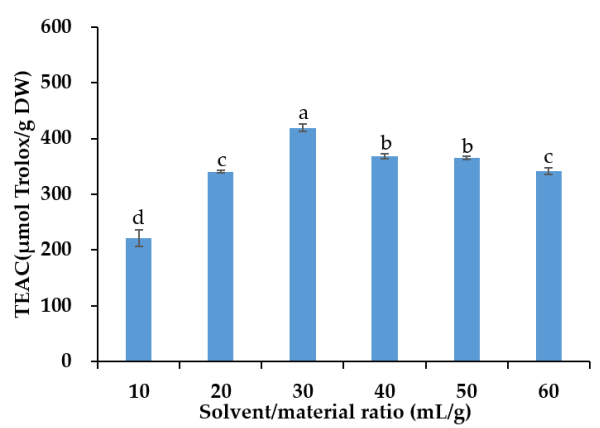

(b)

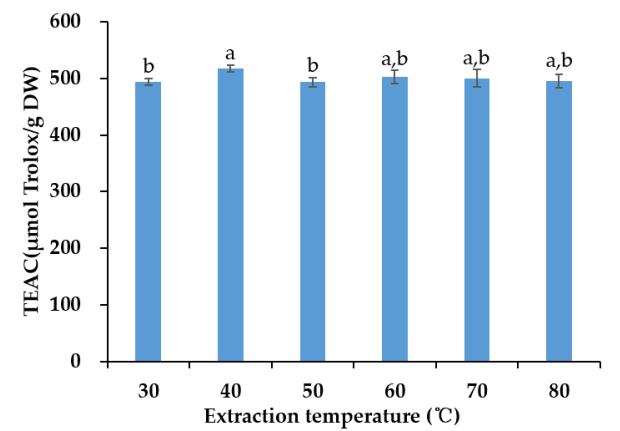

(d)

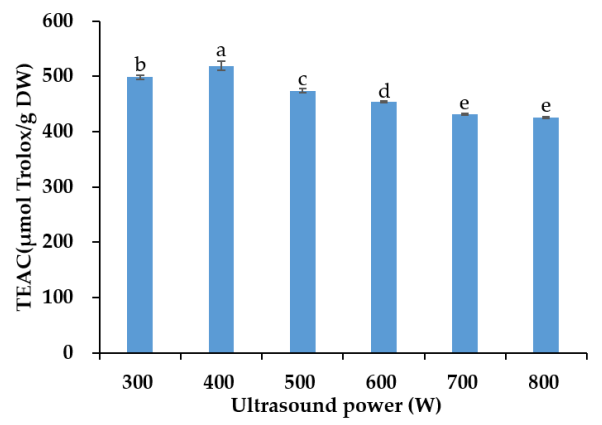

(e)

Figure 2. Effects of ethanol concentration (a), solvent/material ratio (b), extraction time (c), extraction temperature (d), and ultrasonication power (e) on the extraction efficacy. Different lowercase letters indicated statistical significance $(P<0.05)$. TEAC, Trolox equivalent antioxidant capacity.

Figure $2 \mathrm{~d}$ illustrates the influences of extraction temperature $\left(30-80^{\circ} \mathrm{C}\right)$ on the yield of antioxidants. The rest parameters were fixed at $40 \%$ ethanol concentration, $30 \mathrm{~mL} / \mathrm{g} \mathrm{S} / \mathrm{M}$ ratio, 60 min extraction time, and $400 \mathrm{~W}$ ultrasonication power. The yield of antioxidants increased as the increase of temperature, and reached its maximum at the temperature of $40{ }^{\circ} \mathrm{C}$, which was $516.94 \pm 5.93 \mu \mathrm{mol}$ Trolox/g DW. When the temperature exceeded $40^{\circ} \mathrm{C}$, the yield of antioxidants dropped down, probably due to the degradation of some heat labile compounds at higher temperature. Consistently, it was reported that when extracting phenolic compounds from peel of Citrus unshiu by UAE, excessively high temperature caused decrease in the contents of caffeic acid, ferulic acid, $p$-coumaric acid, and $p$-hydroxybenzoic acid by $48.90,48.23,44.20$, and $35.33 \%$, respectively [32]. Therefore, $40^{\circ} \mathrm{C}$ extraction temperature was selected for the following experiments.

Ultrasonication power could also affect the efficacy of UAE. In this section, the influences of ultrasonication power on the yield of antioxidants were evaluated in the range of 300-800 W, with other parameters fixed at ethanol concentration of $40 \%, \mathrm{~S} / \mathrm{M}$ ratio of $30 \mathrm{~mL} / \mathrm{g}$, extraction time of $60 \mathrm{~min}$ 
and extraction temperature of $40^{\circ} \mathrm{C}$. The results are shown in Figure 2e. When ultrasonication power increased from 300 to $400 \mathrm{~W}$, the yield of antioxidants increased, and the yield of phenolic compounds reached the maximum at the ultrasonication power of $400 \mathrm{~W}$, and then gradually decreased. A possible explanation is that high ultrasonication power could induce the cavitation phenomena, the formation and collapse of more bubbles, thereby elevating the yield of target compounds. However, excessively strong ultrasonication power might decompose some compounds in the extracts, causing a lower yield of target compounds $[33,34]$. Consequently, the ultrasonication power of $400 \mathrm{~W}$ was selected in the experiments.

\subsection{Results of Response Surface Methodology Experiments}

\subsubsection{Central Composite Rotatable Design (CCRD) and Results}

According to the single-factor experimental results, ethanol concentration, S/M ratio, and extraction time had greater effects on the extraction efficacy. Therefore, they were further investigated for their possible interaction (Figure 3) by response surface methodology to optimize the extraction efficacy. The middle level of each parameter was fixed as follows, $40 \%$ ethanol concentration, $30 \mathrm{~mL} / \mathrm{g} \mathrm{S} / \mathrm{M}$ ratio, and 60 min extraction time, while the extraction temperature and ultrasonication power were fixed at $40{ }^{\circ} \mathrm{C}$ and $400 \mathrm{~W}$, respectively. The experimental design, experimental values, and predicted values of the 20 runs are shown in Table 2. The TEAC value varied from 212.50 to $603.38 \mu$ mol Trolox/g DW.

\subsubsection{Fitting the Model}

The data in Table 2 were analyzed using multiple regression fitting, and a quadratic polynomial regression model equation (2) describing the relationship between the response value and the three variables was generated:

$$
Y=531.11-0.62 X_{1}+12.07 X_{2}-1.82 X_{3}-23.67 X_{1} X_{2}+38.29 X_{1} X_{3}-26.85 X_{2} X_{3}-96.61 X_{1}^{2}-72.26 X_{2}^{2}-72.34 X_{3}^{2}
$$

Results of ANOVA is displayed in Table 3. The high $F$ value $(F=15.02)$ and low $p$ value $(p=0.0001)$ of the model, and the low $F$ value $(F=1.74)$ and high $p$ value $(p=0.2791)$ of "lack of fit" indicated the reliability of the generated model. In addition, the high determination coefficient value $\left(\mathrm{R}^{2}\right)$ of 0.9311 , and the adjusted $\mathrm{R}^{2}$ value (Adj. $\mathrm{R}^{2}$ ) of 0.8691 suggested that the regression model could explain $93.1 \%$ of the response value variations.

Table 3. ANOVA of the fitted polynomial quadratic model.

\begin{tabular}{|c|c|c|c|c|c|c|}
\hline Source & $\begin{array}{l}\text { Sum of } \\
\text { Squares }\end{array}$ & df & $\begin{array}{l}\text { Mean } \\
\text { Square }\end{array}$ & $F$ Value & $p$ Value & Significant \\
\hline Model & $2.635 \times 10^{5}$ & 9 & 29279.68 & 15.02 & 0.0001 & \multirow[t]{11}{*}{ significant } \\
\hline $\mathrm{X}_{1}$ (Ethanol concentration) & 5.21 & 1 & 5.21 & $2.673 \times 10^{-3}$ & 0.9598 & \\
\hline $\mathrm{X}_{2}$ (Solvent/material ratio) & 1988.99 & 1 & 1988.99 & 1.02 & 0.3363 & \\
\hline $\mathrm{X}_{3}$ (Time) & 44.99 & 1 & 44.99 & 0.023 & 0.8823 & \\
\hline $\mathrm{X}_{1} \mathrm{X}_{2}$ & 4484.03 & 1 & 4484.03 & 2.30 & 0.1604 & \\
\hline$x_{1} x_{3}$ & 11730.86 & 1 & 11730.86 & 6.02 & 0.0341 & \\
\hline$x_{2} x_{3}$ & 5768.58 & 1 & 5768.58 & 2.96 & 0.1162 & \\
\hline $\mathrm{X}_{1}^{2}$ & $1.345 \times 10^{5}$ & 1 & $1.345 \times 10^{5}$ & 68.98 & $<0.0001$ & \\
\hline$x_{2}^{2}$ & 75240.48 & 1 & 75240.48 & 38.59 & $<0.0001$ & \\
\hline$x_{3}^{2}$ & 75423.11 & 1 & 75423.11 & 38.68 & $<0.0001$ & \\
\hline Residual & 19499.88 & 10 & 1949.99 & \multirow{6}{*}{1.74} & \multirow{6}{*}{0.2791} & \\
\hline Lack of Fit & 12381.50 & 5 & 2476.30 & & & \multirow[t]{5}{*}{$\begin{array}{c}\text { not } \\
\text { significant }\end{array}$} \\
\hline Pure Error & 7118.37 & 5 & 1423.67 & & & \\
\hline Cor Total & $2.830 \times 10^{5}$ & 19 & & & & \\
\hline R-Squared & 0.9311 & & & & & \\
\hline Adj R-Squared & 0.8691 & & & & & \\
\hline
\end{tabular}




\subsubsection{Analysis of Response Surface Plots}

The three-dimensional plots of response surface (Figure 3) illustrated the interaction of two of the three major factors on the yield of antioxidants when the third one was fixed at a certain level. Figure $3 a$ shows the combined effect of ethanol concentration and $\mathrm{S} / \mathrm{M}$ ratio when the extraction time was fixed at $60 \mathrm{~min}$. Both ethanol concentration and $\mathrm{S} / \mathrm{M}$ ratio had effects on the yield of antioxidants. The yield of antioxidants gradually increased when the ethanol concentration increased in a certain range, and when the ethanol concentration exceeded about $40 \%$, the yield of antioxidants began to decrease. As for the S/M ratio, the yield of antioxidants increased at low S/M ratio (20-35\%), and gradually decreased when the $\mathrm{S} / \mathrm{M}$ ratio further increased. The interaction between ethanol concentration and extraction time is shown in Figure $3 \mathrm{~b}$. The yield of antioxidants changed with the ethanol concentration or extraction time when the $\mathrm{S} / \mathrm{M}$ ratio was fixed at $30 \mathrm{~mL} / \mathrm{g}$. In Figure $3 \mathrm{~b}$, a similar influence of ethanol concentration on the response value was observed. As for the extraction time, the TEAC value gradually increased as the extracting time rising. When the extracting time exceeded nearly $60 \mathrm{~min}$, the TEAC value gradually decreased. In Figure $3 c$, the S/M ratio and extracting time also showed similar effects on the response value with that shown in Figure 3a,b. Combining the response surface plots and the ANOVA results in Table 3, conclusions could be drawn that the effect of each independent variable on the response value was quadratic. In addition, the $\mathrm{S} / \mathrm{M}$ ratio had a more significant effect on the response value than the ethanol concentration and extracting time.

\subsubsection{Verification of the Predicted Value}

The generated quadratic polynomial regression model gave the optimal extraction conditions with a desirability of 0.663 . The optimal extraction conditions were as follows: $39.78 \%$ ethanol concentration, $30.94 \mathrm{~mL} / \mathrm{g} \mathrm{S} / \mathrm{M}$ ratio, $59.47 \mathrm{~min}$ extraction time, $40{ }^{\circ} \mathrm{C}$ temperature, and $400 \mathrm{~W}$ ultrasonication power. The yield of antioxidants under the optimal conditions was predicted to be $531.71 \mu$ mol Trolox/g DW. In order to verify the model's ability to accurately predict the actual value, verification experiments (six replicates) under the optimal conditions were carried out, and the result was $525.05 \pm 14.34 \mu \mathrm{mol}$ Trolox/g DW, which was close to the predicted value.
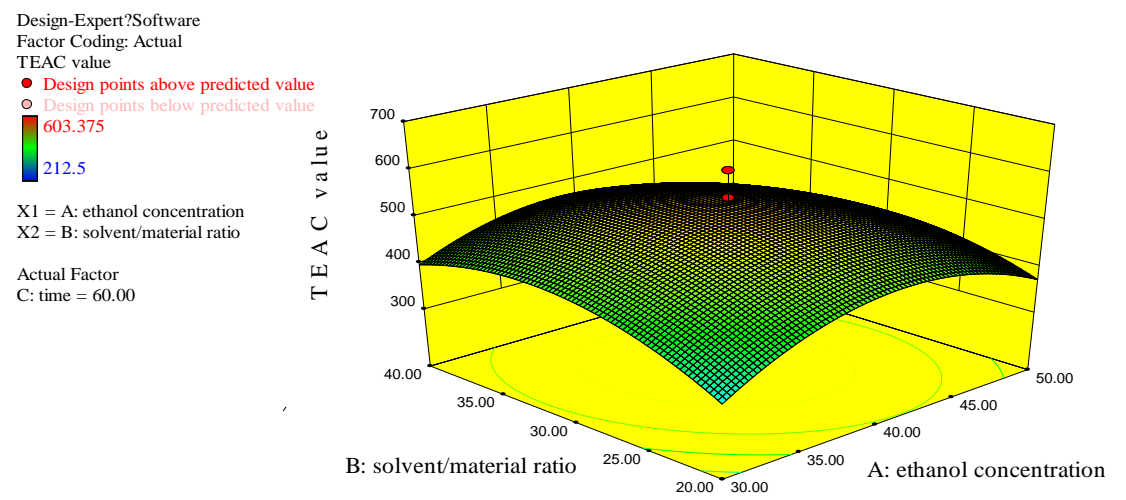

(a)

Figure 3. Cont. 

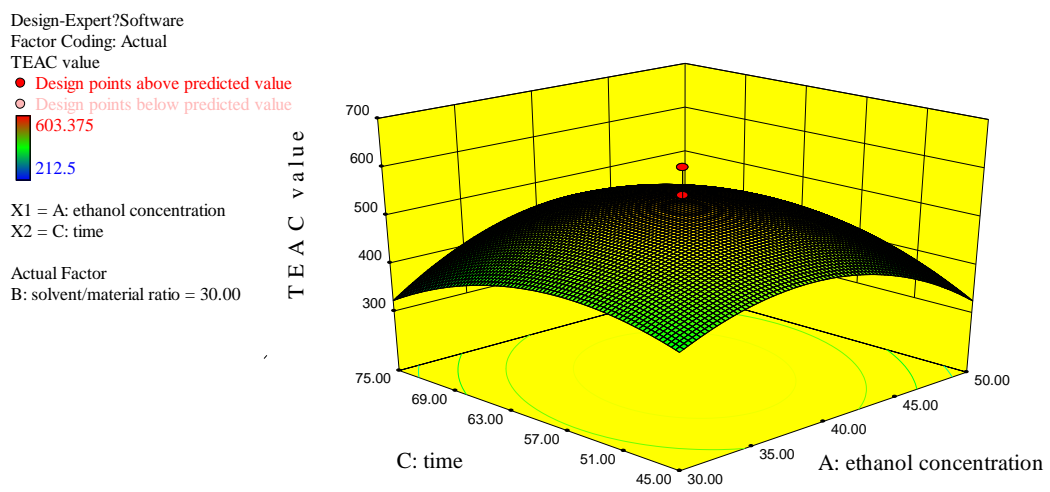

(b)
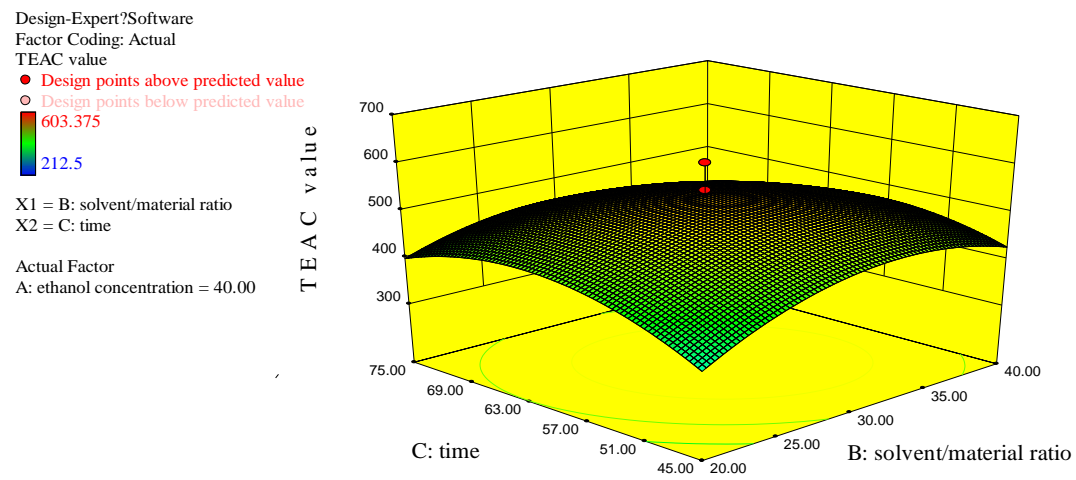

(c)

Figure 3. The three-dimensional plots of response surface. (a) The combined effects of ethanol concentration and solvent/material ratio (S/M) ratio when the extraction time was fixed at $60 \mathrm{~min}$; (b) The interaction between ethanol concentration and extraction time when $\mathrm{S} / \mathrm{M}$ ratio was fixed at $30 \mathrm{~mL} / \mathrm{g}$; (c) The combined effect of extraction time and $\mathrm{S} / \mathrm{M}$ ratio when the ethanol concentration was fixed at $40 \%$. TEAC, Trolox equivalent antioxidant capacity.

\subsection{Comparison of UAE with Two Conventional Extraction Methods}

Maceration and Soxhlet extraction are two conventional extraction methods which are commonly used to extract bioactive components from natural products $[35,36]$. Therefore, the efficacy of UAE was compared with that of maceration and Soxhlet extraction, and the results are displayed in Table 4. The TEAC value of UAE procedure was 2.26 times higher than that of maceration. Meanwhile, the UAE required much shorter time ( $59.47 \mathrm{~min}$ vs. $24 \mathrm{~h}$ ), and the TPC and TFC of the extract obtained by UAE were both higher than those obtained by maceration. In addition, compared with the Soxhlet extraction, the UAE enhanced the extraction efficacy by 3.62 times, with a lower temperature $\left(40^{\circ} \mathrm{C}\right.$ vs. $85^{\circ} \mathrm{C}$ ) and shorter time (59.47 min vs. $4 \mathrm{~h}$ ). In addition, UAE also increased the yield of phenolic compounds and flavonoids compounds from the Gordonia axillaris fruit. Similar results were reported to extract antioxidants from the flower of Limonium sinuatum, in which the established UAE method extracted significantly higher content of antioxidants than Soxhlet extraction [37]. Another study also found that $10 \mathrm{~min}$ of ultrasound-assisted extraction of phenolic-rich heteroxylans from wheat bran yielded total polysaccharides similar to $60 \mathrm{~min}$ of conventional extraction, indicating that UAE reduced the process time [38]. In addition, UAE improved the extraction efficiency with shorter extraction time and higher TEAC, TPC, and TFC values for Gordonia axillaris fruits compared with microwave-assisted extraction (MAE), with the extraction time of $71.04 \mathrm{~min}$, TEAC value of $198.16 \pm 5.47 \mu \mathrm{mol}$ Trolox/g DW, TFC value of $17.69 \pm 1.02 \mathrm{mg}$ GAE/g DW, and TPC value of $3.11 \pm 0.12 \mathrm{mg}$ QE/g DW [8]. 
Table 4. The comparison of UAE with the maceration and Soxhlet extraction.

\begin{tabular}{ccccccc}
\hline $\begin{array}{c}\text { Extraction } \\
\text { Methods }\end{array}$ & $\begin{array}{c}\text { Ethanol } \\
\text { Conc. }(\%)\end{array}$ & Time & Temp. $\left({ }^{\circ} \mathrm{C}\right)$ & $\begin{array}{c}\text { TEAC }(\mu \mathrm{mol} \\
\text { Trolox/g DW) }\end{array}$ & $\begin{array}{c}\text { TPC }(\mathbf{m g} \\
\text { GAE/g DW) }\end{array}$ & $\begin{array}{c}\text { TFC }(\mathbf{m g} \\
\text { QE/g DW) }\end{array}$ \\
\hline Maceration & 39.78 & $24 \mathrm{~h}$ & 25 & $161.25 \pm 2.29$ & $13.16 \pm 2.43$ & $1.86 \pm 0.12$ \\
Soxhlet & 39.78 & $4 \mathrm{~h}$ & 85 & $113.77 \pm 2.58$ & $9.02 \pm 0.78$ & $1.77 \pm 0.22$ \\
UAE & 39.78 & $59.47 \mathrm{~min}$ & 40 & $525.05 \pm 14.34$ & $43.45 \pm 3.16$ & $3.22 \pm 0.44$ \\
\hline
\end{tabular}

TEAC, Trolox equivalent antioxidant capacity; TPC, Total phenolic contents; TFC, Total flavonoid contents; UAE, Ultrasonic-assisted extraction.

\subsection{Phenolic Compounds in Extracts}

UPLC-MS/MS was next used to characterize the phenolic profile in the extract of Gordonia axillaris fruit acquired under the optimal condition of UAE. The total ion chromatograms of standard compounds and the sample acquired under the optimal conditions are shown in Figure 4. Nine phenolic compounds were identified and quantified (Table 5). Rutin had the highest content $(21.86 \pm 3.38 \mu \mathrm{g} / \mathrm{g}$ $\mathrm{DW})$, followed by gallic acid $(17.80 \pm 2.68 \mu \mathrm{g} / \mathrm{g} D W)$, protocatechuic acid $(10.81 \pm 2.54 \mu \mathrm{g} / \mathrm{g} D W)$, epicatechin (3.89 $\pm 0.43 \mu \mathrm{g} / \mathrm{g} \mathrm{DW}), 2$-hydrocinnamic acid $(2.68 \pm 0.25 \mu \mathrm{g} / \mathrm{g} \mathrm{DW}), p$-coumaric acid $(2.67 \pm 0.22 \mu \mathrm{g} / \mathrm{g} \mathrm{DW})$, quercetin $(2.45 \pm 0.21 \mu \mathrm{g} / \mathrm{g} \mathrm{DW})$, epicatechin gallate $(1.07 \pm 0.11 \mu \mathrm{g} / \mathrm{g} \mathrm{DW})$, and ferulic acid $(0.12 \pm 0.01 \mu \mathrm{g} / \mathrm{g}$ DW). The contents of phenolic compounds in this study based on UAE were found different compared to those reported in a previous paper using MAE [8], probably due to the different extraction conditions, such as the different extraction mechanisms and extraction time between UAE and MAE.

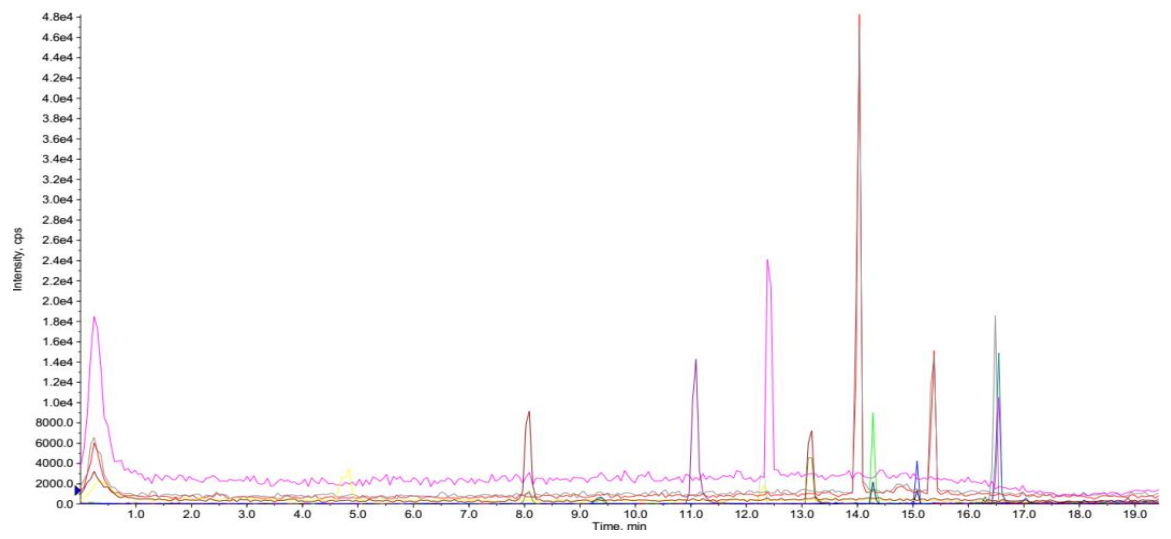

(a)

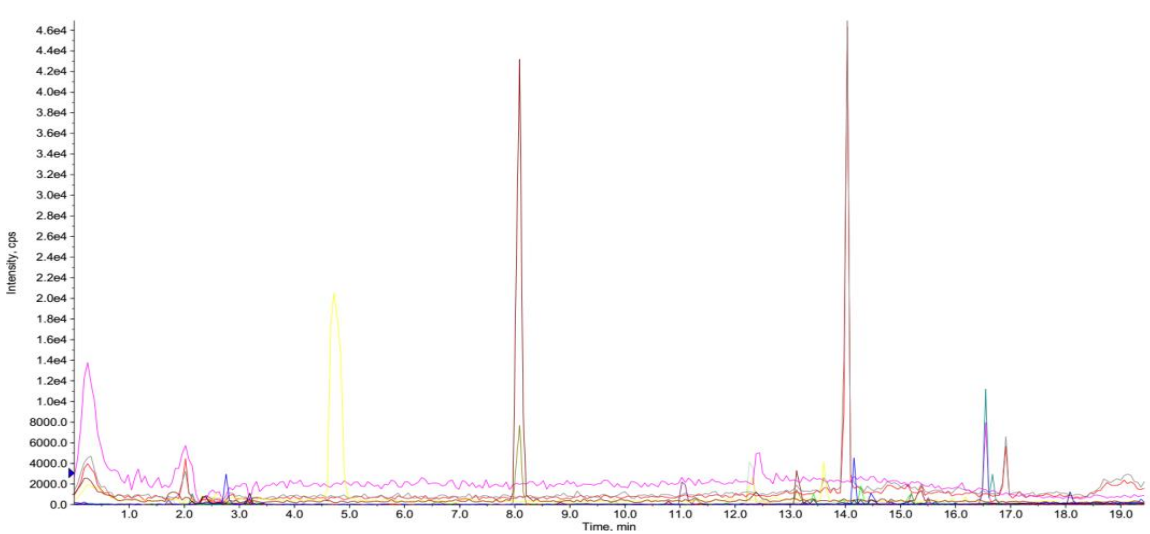

(b)

Figure 4. (a) The total ion chromatograms of standard compounds; (b) The total ion chromatograms of the sample obtained under the optimal conditions. Different colors in the figure indicated different compounds. 
Table 5. The phenolic profile in the extract acquired under the optimal conditions of UAE.

\begin{tabular}{ccccc}
\hline Phenolic Components & $\begin{array}{c}\text { Retention Time } \\
\left(\boldsymbol{t}_{\mathbf{R}}, \mathbf{m i n}\right)\end{array}$ & $\begin{array}{c}\text { Parent Ion }(\boldsymbol{m} / \boldsymbol{z}, \\
\left.[\mathbf{M}-\mathbf{H}]^{-}\right)\end{array}$ & Product Ion $(\boldsymbol{m} / \mathbf{z})$ & $\begin{array}{c}\text { Contents } \\
(\boldsymbol{\mu} \mathbf{g} / \mathbf{g} \mathbf{D})\end{array}$ \\
\hline Rutin & 14.77 & 609 & 300,343 & $21.86 \pm 3.38$ \\
Gallic acid & 4.76 & 169.1 & 125,112 & $17.80 \pm 2.68$ \\
Protocatechuic acid & 8.07 & 153.1 & 109,108 & $10.81 \pm 2.54$ \\
Epicatechin & 12.3 & 289 & 203,245 & $3.89 \pm 0.43$ \\
2-Hydrocinnamic acid & 14.03 & 163.1 & 119,90 & $2.68 \pm 0.25$ \\
p-Coumaric acid & 14.03 & 162.7 & 119,90 & $2.67 \pm 0.22$ \\
Quercetin & 16.54 & 301 & 179,151 & $2.45 \pm 0.21$ \\
Epicatechin gallate & 13.13 & 441 & $169,289.1$ & $1.07 \pm 0.09$ \\
Ferulic acid & 14.28 & 193.1 & 134,178 & $0.12 \pm 0.01$ \\
\hline
\end{tabular}

\section{Conclusions}

In this study, an ultrasonic-assisted extraction method was developed to extract natural antioxidant polyphenols from the fruit of Gordonia axillaris, and single-factor experiments, and response surface methodology were used to acquire optimal extraction parameters. A quadratic polynomial regression model was established, and the optimal conditions were as follows: ethanol concentration at $39.78 \%$, $\mathrm{S} / \mathrm{M}$ ratio at $30.94 \mathrm{~mL} / \mathrm{g}$, extraction time at $59.47 \mathrm{~min}$, temperature at $40^{\circ} \mathrm{C}$, and ultrasonication power at $400 \mathrm{~W}$. Under the optimal conditions, the yield of antioxidants was $525.05 \pm 14.34 \mu \mathrm{mol}$ Trolox/g DW. The high $R^{2}$ (0.9311) and the consistency between the predicted value and actual value suggested that this model could accurately predict the effects of the three major factors on the yield of antioxidants. Additionally, the optimized UAE method was more efficient than two conventional methods in extracting antioxidants from Gordonia axillaris fruits. Furthermore, nine phenolic compounds were identified and quantified by UPLC-MS/MS in the extract obtained under the optimal conditions. These phenolic compounds may be responsible for the strong antioxidant capacity of Gordonia axillaris fruits. In the future, the extract of the fruits can be developed into functional food or nutraceuticals with the potential to prevent certain oxidative stress-related chronic diseases.

Author Contributions: Conceptualization, Y.L., S.-Y.C., R.-Y.G. and H.-B.L.; Funding acquisition, R.-Y.G.; Investigation, Y.L. and S.-J.L.; Methodology, Y.L. and S.-Y.C.; Resources, Y.L.; Software, S.-Y.C.; Supervision, R.-Y.G. and H.-B.L.; Validation, Y.L. and S.-Y.C.; Writing - original draft, Y.L. and S.-Y.C.; Writing - review \& editing, J.-R.Z., R.-Y.G. and H.-B.L.

Funding: This study was funded by the Shanghai Basic and Key Program (18JC1410800), the Shanghai Agricultural Science and Technology Key Program (18391900600), Shanghai Pujiang Talent Plan (18PJ1404600), and the Agri-X Interdisciplinary Fund of Shanghai Jiao Tong University (Agri-X2017004).

Conflicts of Interest: The authors declare no conflict of interest.

\section{References}

1. Fu, L.; Xu, B.T.; Xu, X.R.; Gan, R.Y.; Zhang, Y.; Xia, E.Q.; Li, H.B. Antioxidant capacities and total phenolic contents of 62 fruits. Food Chem. 2011, 129, 345-350. [CrossRef] [PubMed]

2. Li, Y.; Zhang, J.J.; Xu, D.P.; Zhou, T.; Zhou, Y.; Li, S.; Li, H.B. Bioactivities and health benefits of wild fruits. Int. J. Mol. Sci. 2016, 17, 1258. [CrossRef] [PubMed]

3. Li, Y. Extraction of Bioactive Components from Gordonia axillaris Fruit and the Hepatoprotective Effect. Master's Thesis, Sun Yat Sen University, Guangzhou, China, 2018.

4. Chang, C.W.; Yang, L.L.; Yen, K.Y.; Hatano, T.; Yoshida, T.; Okuda, T. Tannins from Theaceous plants. VII. new. Gamma-pyrone glucoside, and dimeric ellagitannins from Gordonia axillaris. Chem. Pharm. Bull. 1994, 42, 1922-1923. [CrossRef]

5. Power, M.; de Thompson, M.C.; Heese, H.V.; Louw, H.H.; Khan, M.B. Priorities for provision of health care services for children in the Cape Province. S. Afr. Med. J. 1991, 80, 481-486. [PubMed]

6. Wang, C.C.; Chen, L.G.; Yang, L.L. Camelliin B induced apoptosis in HeLa cell line. Toxicology 2001, 168, 231-240. [CrossRef] 
7. Fu, L.; Xu, B.T.; Xu, X.R.; Qin, X.S.; Gan, R.Y.; Li, H.B. Antioxidant capacities and total phenolic contents of 56 wild fruits from South China. Molecules 2010, 15, 8602-8617. [CrossRef]

8. Li, Y.; Li, S.; Lin, S.J.; Zhang, J.J.; Zhao, C.N.; Li, H.B. Microwave-assisted extraction of natural antioxidants from the exotic Gordonia axillaris fruit: Optimization and identification of phenolic compounds. Molecules 2017, 22, 1481. [CrossRef]

9. Bagheri, H.; Esmaiili, M. Ultrasound-assisted extraction of phenolic compounds from unripe grape (Qora). Erwerbs-Obstbau 2017, 59, 221-226. [CrossRef]

10. Pereira, M.G.; Hamerski, F.; Andrade, E.F.; Scheer, A.D.; Corazza, M.L. Assessment of subcritical propane, ultrasound-assisted and Soxhlet extraction of oil from sweet passion fruit (Passiflora alata Curtis) seeds. J. Supercrit. Fluid. 2017, 128, 338-348. [CrossRef]

11. Cravotto, G.; Cintas, P. Power ultrasound in organic systhesis: Moving cavitational chemistry from academia to innovative and large-scale applications. Chem. Soc. Rev. 2006, 35, 180-196. [CrossRef]

12. Xu, D.P.; Zheng, J.; Zhou, Y.; Li, Y.; Li, S.; Li, H.B. Ultrasound-assisted extraction of natural antioxidants from the flower of Limonium sinuatum: Optimization and comparison with conventional methods. Food Chem. 2017, 217, 552-559. [CrossRef]

13. Chemat, F.; Rombaut, N.; Sicaire, A.G.; Meullemiestre, A.; Fabiano-Tixier, A.S.; Abert-Vian, M. Ultrasound assisted extraction of food and natural products. Mechanisms, techniques, combinations, protocols and applications: A review. Ultrason. Sonochem. 2017, 34, 540-560. [CrossRef] [PubMed]

14. Xu, D.P.; Li, Y.; Meng, X.; Zhou, T.; Zhou, Y.; Zheng, J.; Zhang, J.J.; Li, H.B. Natural antioxidants in foods and medicinal plants: Extraction, assessment and resources. Int. J. Mol. Sci. 2017, 18, 96. [CrossRef] [PubMed]

15. Xu, D.P.; Zhou, Y.; Zheng, J.; Li, S.; Li, A.N.; Li, H.B. Optimization of ultrasound-assisted extraction of natural antioxidants from the flower of Jatropha integerrima by response surface methodology. Molecules 2016, 21, 18. [CrossRef] [PubMed]

16. Deng, G.F.; Xu, D.P.; Li, S.; Li, H.B. Optimization of ultrasound-assisted extraction of natural antioxidants from sugar apple (Annona squamosa L.) peel using response surface methodology. Molecules 2015, 20, 20448-20459. [CrossRef]

17. Zhou, T.; Xu, D.P.; Lin, S.J.; Li, Y.; Zheng, J.; Zhou, Y.; Zhang, J.J.; Li, H.B. Ultrasound-assisted extraction and identification of natural antioxidants from the fruit of Melastoma sanguineum Sims. Molecules 2017, 22, 306. [CrossRef] [PubMed]

18. Espada-Bellido, E.; Ferreiro-González, M.; Carrera, C.; Palma, M.; Barroso, C.G.; Barbero, G.F. Optimization of the ultrasound-assisted extraction of anthocyanins and total phenolic compounds in mulberry (Morus nigra) pulp. Food Chem. 2017, 219, 23-32. [CrossRef] [PubMed]

19. Severini, C.; Derossi, A.; Fiore, A.G. Ultrasound-assisted extraction to improve the recovery of phenols and antioxidants from spent espresso coffee ground: A study by response surface methodology and desirability approach. Eur. Food Res. Technol. 2017, 243, 835-847. [CrossRef]

20. Shirzad, H.; Niknam, V.; Taheri, M.; Ebrahimzadeh, H. Ultrasound-assisted extraction process of phenolic antioxidants from olive leaves: A nutraceutical study using RSM and LC-ESI-DAD-MS. J. Food Sci. Tech. 2017, 54, 2361-2371. [CrossRef]

21. Re, R.; Pellegrini, N.; Proteggente, A.; Pannala, A.; Yang, M.; Rice-Evans, C. Antioxidant activity applying an improved ABTS radical cation decolorization assay. Free Radic. Biol. Med. 1999, 26, 1231-1237. [CrossRef]

22. Li, A.N.; Li, S.; Li, H.B.; Xu, D.P.; Xu, X.R.; Chen, F. Total phenolic contents and antioxidant capacities of 51 edible and wild flowers. J. Funct. Foods 2014, 6, 319-330. [CrossRef]

23. Kim, D.O.; Chun, O.K.; Kim, Y.J.; Moon, H.Y.; Lee, C.Y. Quantification of polyphenolics and their antioxidant capacity in fresh plums. J. Agric. Food Chem. 2003, 51, 6509-6515. [CrossRef]

24. Chotphruethipong, L.; Benjakul, S.; Kijroongrojana, K. Optimization of extraction of antioxidative phenolic compounds from cashew (Anacardium occidentale L.) leaves using response surface methodology. J. Food Biochem. 2017, 41, e12379. [CrossRef]

25. Da Silva, M.F.; Casazza, A.A.; Ferrari, P.F.; Aliakbarian, B.; Converti, A.; Bezerra, R.P.; Porto, A.; Perego, P. Recovery of phenolic compounds of food concern from Arthrospira platensis by green extraction techniques. Algal Res. 2017, 25, 391-401. [CrossRef]

26. Li, A.N.; Li, S.; Li, Y.; Xu, D.P.; Li, H.B. Optimization of ultrasound-assisted extraction of natural antioxidants from the Osmanthus fragrans flower. Molecules 2016, 21, 218. [CrossRef] 
27. Li, A.N.; Li, S.; Xu, D.P.; Xu, X.R.; Chen, Y.M.; Ling, W.H.; Chen, F.; Li, H.B. Optimization of ultrasound-Assisted extraction of lycopene from papaya processing waste by response surface methodology. Food Anal. Methods 2015, 8, 1207-1214. [CrossRef]

28. Ghitescu, R.E.; Volf, I.; Carausu, C.; Buhlmann, A.M.; Gilca, I.A.; Popa, V.I. Optimization of ultrasound-assisted extraction of polyphenols from spruce wood bark. Ultrason. Sonochem. 2015, 22, 535-541. [CrossRef]

29. Xu, Y.; Pan, S.Y. Effects of various factors of ultrasonic treatment on the extraction yield of all-trans-lycopene from red grapefruit (Citrus paradise Macf.). Ultrason. Sonochem. 2013, 20, 1026-1032. [CrossRef] [PubMed]

30. Peng, L.; Jia, X.; Wang, Y.; Zhu, H.; Chen, Q. Ultrasonically assisted extraction of rutin from Artemisia selengensis Turcz: Comparison with conventional extraction techniques. Food Anal. Methods 2010, 3, 261-268. [CrossRef]

31. Xia, E.Q.; Yu, Y.Y.; Xu, X.R.; Deng, G.F.; Guo, Y.J.; Li, H.B. Ultrasound-assisted extraction of oleanolic acid and ursolic acid from Ligustrum lucidum Ait. Ultrason. Sonochem. 2012, 19, 772-776. [CrossRef]

32. Ma, Y.Q.; Ye, X.Q.; Fang, Z.X.; Chen, J.C.; Xu, G.H.; Liu, D.H. Phenolic compounds and antioxidant activity of extracts from ultrasonic treatment of Satsuma mandarin (Citrus unshiu Marc.) peels. J. Agric. Food Chem. 2008, 56, 5682-5690. [CrossRef]

33. Chen, F.L.; Zhang, Q.; Fei, S.M.; Gu, H.Y.; Yang, L. Optimization of ultrasonic circulating extraction of samara oil from Acer saccharum using combination of Plackett-Burman design and Box-Behnken design. Ultrason. Sonochem. 2017, 35, 161-175. [CrossRef]

34. Yue, T.L.; Shao, D.Y.; Yuan, Y.H.; Wang, Z.L.; Qiang, C.Y. Ultrasound-assisted extraction, HPLC analysis, and antioxidant activity of polyphenols from unripe apple. J. Sep. Sci. 2012, 35, 2138-2145. [CrossRef] [PubMed]

35. Ma, S.Q.; Tu, X.J.; Dong, J.T.; Long, P.; Yang, W.C.; Miao, X.Q.; Chen, W.B.; Wu, Z.H. Soxhlet-assisted matrix solid phase dispersion to extract flavonoids from rape (Brassica campestris) bee pollen. J. Chromatogr. B. 2015, 1005, 17-22. [CrossRef]

36. Subramanian, R.; Subbramaniyan, P.; Ameen, J.N.; Raj, V. Double bypasses soxhlet apparatus for extraction of piperine from Piper nigrum. Arab. J. Chem. 2016, 91, S537-S540. [CrossRef]

37. Dent, M.; Dragović-Uzelac, V.; Garofulić, I.E.; Bosiljkov, T.; Ježek, D.; Brnčić, M. Comparison of conventional and ultrasound-assisted extraction techniques on mass fraction of phenolic compounds from Sage (Salvia officinalis L.). Chem. Biochem. Eng. Q. 2015, 29, 475-484. [CrossRef]

38. Hromadkova, Z.; Kost'Alova, Z.; Ebringerova, A. Comparison of conventional and ultrasound-assisted extraction of phenolics-rich heteroxylans from wheat bran. Ultrason. Sonochem. 2008, 15, 1062-1068. [CrossRef] [PubMed]

(C) 2019 by the authors. Licensee MDPI, Basel, Switzerland. This article is an open access article distributed under the terms and conditions of the Creative Commons Attribution (CC BY) license (http://creativecommons.org/licenses/by/4.0/). 